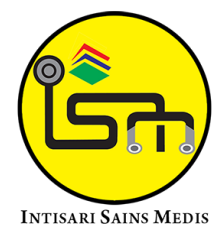

Published by Intisari Sains Medis

\title{
Pengembangan sistem pengelolaan alat kesehatan pada ruang perawatan berbasis teknologi informasi di RSUD Sanjiwani, Gianyar tahun 2021
}

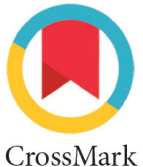

CrossMark

Ni Made Milapastiniari ${ }^{1,2^{*}}$, I Gede Putu Darma Suyasa ${ }^{1}$, I Ketut Alit Adianta ${ }^{1}$, Ni Kadek Sriasih ${ }^{1}$

\section{ABSTRACT}

Background: Health equipment is one of the important factors in the implementation of health services. An increase in the number and types of medical equipment requires a good management system, so that the number, condition and presence can be monitored at any time. Currently, there is no system that can facilitate the management of medical devices in the treatment room so that it can be integrated with other units in the hospital. The purpose of this study was to develop an information system for managing medical devices in an appropriate and efficient treatment room based on the managerial functions of the head of the room.

Methods: The type of research used is action research where total sampling is done on 29 employees of RSUD Sanjiwani Gianyar This research consists of six stages, namely Focus Group Discussion (FGD), information system design, socialization and testing, evaluation of user satisfaction with information system design, application and evaluation of the real benefits of information systems. Data were analyzed with SPSS version 21 for Windows.

Results: There were thirteen themes obtained through Focus Group Discussions (FGD), then the themes obtained were integrated into the designed information system. After conducting socialization and testing, the researchers evaluated user satisfaction with the design of this information system, where $58.6 \%$ stated that they were satisfied and $41.4 \%$ said they were very satisfied. The application of this information system was carried out for four weeks, and finally an evaluation of the real benefits was carried out. Based on the results of this evaluation, it was found that $51.7 \%$ said this system was useful and $48.3 \%$ said it was very useful.

Conclusion: The development of this medical device management information system is useful to support the task of the head of the room in carrying out the management of medical devices in the treatment room.
'Institut Teknologi dan Kesehatan, Denpasar, Bali, Indonesia;

2Rumah Sakit Umum Daerah (RSUD) Sanjiwani, Gianyar, Bali, Indonesia;

\section{*Korespondensi:}

Ni Made Milapastiniar;

Institut Teknologi dan Kesehatan, Denpasar, Bali, Indonesia;

mila.kum@gmail.com

Keywords: Information Systems, Management, Medical Devices, Treatment Rooms.

Cite This Article: Milapastiniari, N.M., Suyasa, I.G.P.D., Adianta, I.K.A., Sriasih, N.K. 2021. Pengembangan sistem pengelolaan alat kesehatan pada ruang perawatan berbasis teknologi informasi di RSUD Sanjiwani, Gianyar tahun 2021. Intisari Sains Medis 12(3): 735-741. DOI: 10.15562/ism.v12i3.1106

\section{ABSTRAK}

Latar Belakang: Peralatan kesehatan merupakan salah satu faktor penting dalam penyelenggaraan pelayanan kesehatan. Peningkatan jumlah dan jenis peralatan kesehatan, memerlukan sistem pengelolaan yang baik, sehingga jumlah, kondisi dan keberadaannya dapat dipantau setiap waktu. Saat ini belum tersedia sistem yang dapat memfasilitasi pengelolaan alat kesehatan di ruang perawatan sehinga dapat terintegrasi dengan unit- unit terkait yang ada di rumah sakit. Tujuan penelitian ini adalah untuk mengembangkan sistem informasi pengelolaan alat kesehatan di ruang perawatan yang tepat dan efisien berdasarkan fungsi- fungsi manajerial kepala ruangan.

Metode: Jenis penelitian yang digunakan adalah action research dimana pengambilan sampel dilakukan secara total sampling terhadap 29 orang pegawai RSUD Sanjiwani Gianyar Penelitian ini terdiri atas enam tahap yaitu Focus Group Discussion (FGD), perancangan sistem informasi, sosialisasi dan uji coba, evaluasi kepuasan user terhadap rancangan sistem informasi, aplikasi dan evaluasi terhadap manfaat nyata dari sistem informasi. Data dianalisis dengan SPSS versi 21 untuk Windows. Hasil: Terdapat tiga belas tema yang didapatkan melalui Focus Group Discussion (FGD), selanjutnya tema yang didapatkan diintegrasikan kedalam sistem informasi yang dirancang. Setelah dilakukan sosialisasi dan uji coba, peneliti melakukan evaluasi kepuasan user terhadap rancangan sistem informasi ini, dimana didapatkan $58,6 \%$ menyatakan puas dan 
$41,4 \%$ menyatakan sangat puas. Pengaplikasian sistem informasi ini dilaksanakan selama empat minggu, dan terakhir dilakukan evaluasi terhadap manfaat nyata. Berdasarkan hasil evaluasi ini, didapatkan bahwa $51,7 \%$ menyatakan sistem ini bermanfaat dan $48,3 \%$ menyatakan sangat bermanfaat.
Kesimpulan: Pengembangan sistem informasi pengelolaan alat kesehatan ini bermanfaat untuk mendukung tugas kepala ruangan dalam melaksanakan pengelolaan alat kesehatan di ruang perawatan.

Kata kunci: Sistem Informasi, Pengelolaan, Alat Kesehatan, Ruang Perawatan.

Sitasi Artikel ini: Milapastiniari, N.M., Suyasa, I.G.P.D., Adianta, I.K.A., Sriasih, N.K. 2021. Pengembangan sistem pengelolaan alat kesehatan pada ruang perawatan berbasis teknologi informasi di RSUD Sanjiwani, Gianyar tahun 2021. Intisari Sains Medis 12(3): 735-741. D01: 10.15562/ism.v12i3.1106

\section{PENDAHULUAN}

Rumah sakit sebagai institusi pelayanan kesehatan yang kompleks, padat pakar dan padat modal. ${ }^{1}$ Menurut studi yang dilakukan oleh Syahrullah et al., kompleksitas rumah sakit ini muncul karena pelayanan rumah sakit menyangkut berbagai fungsi pelayanan, pendidikan dan penelitian serta mencakup berbagai tingkatan maupun jenis disiplin, agar rumah sakit mampu melaksanakan fungsi yang profesional baik di bidang teknis medis maupun administrasi kesehatan. ${ }^{1}$

Manajemen pelayanan keperawatan adalah pelayanan di rumah sakit yang dikelola oleh bidang perawatan melalui tiga tingkatan manajerial yaitu manajemen puncak (kepala bidang keperawatan), manajemen menengah (kepala unit pelayanan atau supervisor), dan manajemen bawah (kepala ruang perawatan). ${ }^{2}$ Kepala ruangan juga bertugas memastikan tersedianya sarana dan prasarana yang aman, bermutu dan layak pakai serta efisien sehingga meminimalkan risiko yang terkait dengan penggunaan peralatan kesehatan.

Rumah sakit harus memastikan bahwa peralatan medis kritis mereka aman, akurat, andal dan beroperasi pada tingkat kinerja yang diperlukan. Faktanya, berdasarkan data statistik oleh The Joint Commission (TJC) menunjukkan bahwa "sentinel events" yang berhubungan dengan peralatan medis biasanya berada di antara sepuluh jenis teratas setiap tahun. $^{3}$

Kepala ruangan berkewajiban meneruskan informasi tentang penggunaan dan pemeliharaan alat yang diterima dan kemudian melakukan supervisi terkait penggunaan dan pemeliharaan alat tersebut oleh seluruh perawat pelaksana yang bertugas di ruang bersangkutan. Kurangnya kepatuhan terhadap prosedur penggunaan dan pemeliharaan rutin di ruangan, tentu berimbas pada meningkatnya frekuensi gangguan terhadap fungsi ataupun kerusakan pada alat. ${ }^{4} \mathrm{Hal}$ tersebut sesuai dengan hasil sebuah penelitian, dimana disampaikan bahwa dari 297 perawat yang bekerja di ICU di King Saud University Medical City menyelesaikan survei tentang perangkat medis dan pelaporan kejadian yang tidak diharapkan, 198 diantaranya melaporkan mengalami kejadian buruk terkait dengan kegagalan peralatan, sehingga penting untuk mengembangkan kerangka pengoperasian alat kesehatan yang aman berdasarkan standar internasional. ${ }^{4}$

Sebagai rumah sakit rujukan Bali timur dan sebagai rumah sakit pendidikan, beberapa tahun terakhir ini RSUD Sanjiwani, Gianyar sedang berupaya maksimal melengkapi pengadaan alat-alat kesehatan sesuai dengan perkembangan teknologi dan spesialisasi layanan, namun peningkatan pengadaan tersebut belum diimbangi dengan sistem pengelolaan yang baik.

Penggunaan sistem informasi terpadu dalam mengoptimalkan pengelolaan alat kesehatan menjadi hal yang perlu untuk segera dikembangkan. Berdasarkan beberapa penelitian sebelumnya, dengan penggunaan teknologi informasi yang diterapkan melalui sistem informasi pengelolaan alat kesehatan, dapat memberikan kemudahan kepada pengguna dalam melaksanakan pekerjaan, namun kebanyakan sistem informasi tersebut lebih berfokus pada tugas elektromedis dalam pencatatan dam pemeliharaan alat kesehatan. Saat ini belum tersedia sistem yang dapat memfasilitasi pengelolaan alat kesehatan di ruang perawatan yang terintegrasi dengan unit- unit terkait yang ada di rumah sakit. Berdasarkan uraian tersebut, maka penting untuk dilakukan penelitian tentang pengembangan sistem pengelolan alat kesehatan di ruang perawatan berbasis teknologi informasi.

\section{METODE}

Jenis penelitian yang digunakan dalam penelitian ini adalah action research. Metode penelitian tindakan atau action research adalah metode penelitian yang digunakan untuk menguji, mengembangkan, menemukan dan menciptakan tindakan baru, sehingga tindakan tersebut kalau diterapkan dalam pekerjaan, maka proses pelaksanaan kerja akan lebih mudah, lebih cepat, dan hasilnya lebih banyak dan berkualitas. ${ }^{5}$

Tehnik pengambilan sampel yang digunakan adalah total sampling, dimana partisipan dalam penelitian ini merupakan pegawai RSUD Sanjiwani Gianyar, yang tugas pokok dan fungsinya terkait langsung dengan pengelolaan alat kesehatan yang ada di ruang perawatan, yaitu sebanyak 29 orang, terdiri atas 13 orang kepala ruangan, 13 orang perawat inventaris, 1 orang pengurus barang RSUD Sanjiwani, 1 orang staf pengadaan alat kesehatan, 1 orang teknisi alat kesehatan rumah sakit.

Penelitian ini dilaksanakan sesuai tahap-tahap berikut: 1) Focus Group Disscusion (FGD) dan studi dokumentasi untuk mengidentifikasi kebutuhan user terkait sistem informasi pengelolaan alat 
kesehatan yang akan dikembangkan, sesuai dengan fungsi - fungsi manajerial kepala ruangan. Kegiatan FGD dilaksanakan dalam dua sesi untuk membatasi jumlah peserta; 2) Perancangan sistem informasi pengelolaan alat kesehatan di ruang perawatan; 3) Sosialisasi dan uji coba untuk memperkenalkan dan mengujicobakan sistem informasi yang telah dirancang; 4) Evaluasi kepuasan user terhadap sistem yang telah dirancang dengan menggunakan kuesioner End User Computing Satisfaction (EUCS). Model ini dikembangkan oleh Doll \& Torkzadeh dimana keduanya menekankan pada kepuasan (Satisfaction) pengguna akhir terhadap aspek teknologi. Penilaian kepuasan tersebut dilihat dari 5 macam perspektif atau dimensi yaitu: isi (Content), keakuratan (Accuracy), format, kemudahan pengguna (Ease of Use), waktu (Timeliness). ${ }^{6}$ Pengembangan kuesioner ini telah melalui penilaian Content Validity Index (CVI), dimana didapatkan hasil 0,90 ;5) Aplikasi untuk menerapan sistem informasi, yang dilaksanakan selama empat minggu; dan 6) Evaluasi manfaat pengembangan sistem informasi terhadap pengelolaan alat kesehatan di ruang perawatan dengan menggunakan kuesioner yang dikembangkan dari teori Net Benefit. teori ini yang dikembangkan oleh DeLone dan McLean, meliputi pernyataan terkait Improve knowledge sharing, communication effectiveness, reduce informations search time, dan productivities. ${ }^{7}$ Pengembangan kuesioner ini telah melalui penilaian Content Validity Index (CVI), dimana didapatkan hasil 0,90.

Data kualitatif pada penelitian ini dianalisis dengan menggunakan analisa tema, sedangkan data kuantitatif dianalisis dengan menggunakan perangkat piranti lunak komputer SPSS versi 21 untuk Windows.

\section{HASIL}

\section{Hasil FGD dan studi dokumentasi}

Berdasarkan hasil pelaksanaan FGD didapatkan tiga belas tema yang meliputi: Perencanaan dan pengusulan kebutuhan alat kesehatan, pendokumentasian Peminjaman dan mutasi alat kesehatan antar ruangan perawatan, penjadwalan pemeliharaan berkala, penjadwalan

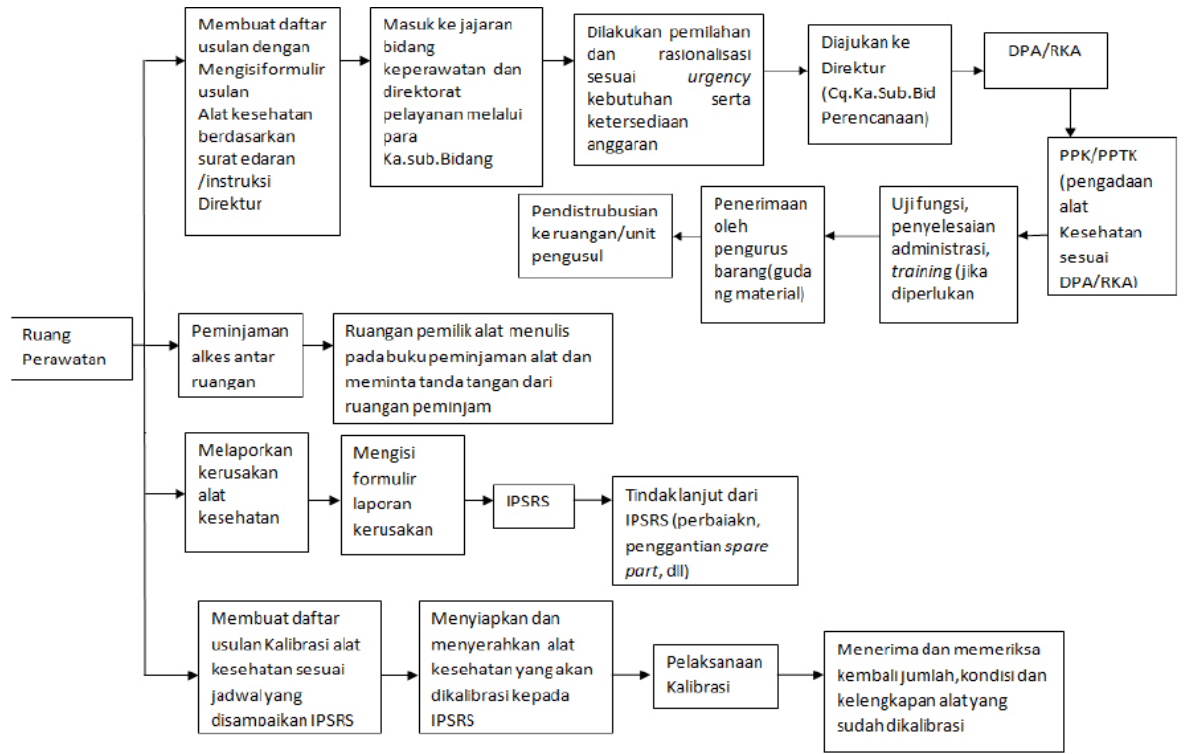

Gambar 1. Alur kerja pengelolaan alat kesehatan di ruang Perawatan sebelum pengembangan sistem informasi.

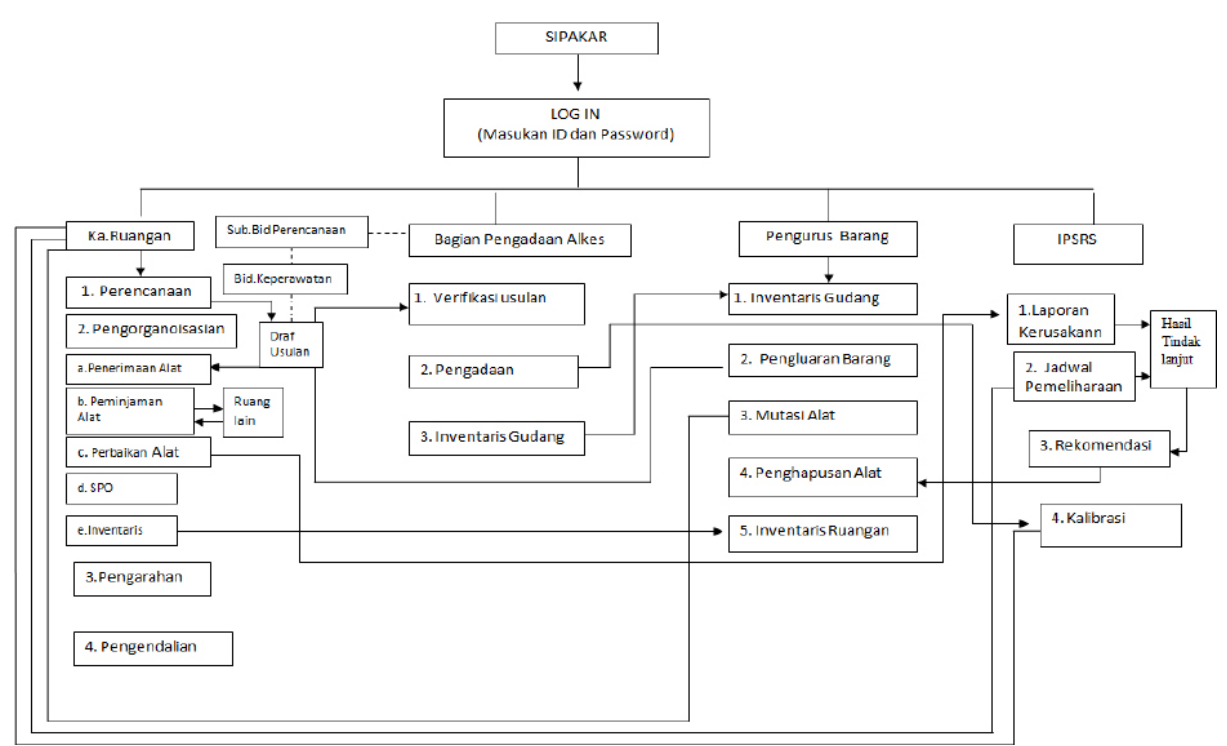

Gambar 2. Alur kerja Sistem Informasi Pengelolaan Alat Kesehatan Ruangan (SIPAKAR).

kalibrasi alat kesehatan, laporan kerusakan alat, keamanan data, fitur untuk diskusi alat kesehatan, penyimpanan SPO pengoperasian dan pemeliharaan alat kesehatan secara online, menu penerimaan alat kesehatan di ruang perawatan, laporan inventaris alat kesehatan, evaluasi alat kesehatan, usulan penghapusan alat kesehatan, dan pedoman tentang kebutuhan alat kesehatan.

Hasil studi dokumentasi terkait kegiatan pengelolaan alat kesehatan di ruangan perawatan didapatkan bahwa kegiatan pengelolaan alat kesehatan masih didokumentasikan secara manual dan belum terintegrasi. Masing masing kegiatan terkait pengelolaan alat kesehatan terdokumentasi secara terpisah. Hal tersebut dapat digambarkan dalam alur kerja sesuai pada Gambar 1.

Hasil Pengembangan sistem informasi Berdasarkan hasil perancangan sistem informasi yang telah dilakukan, 


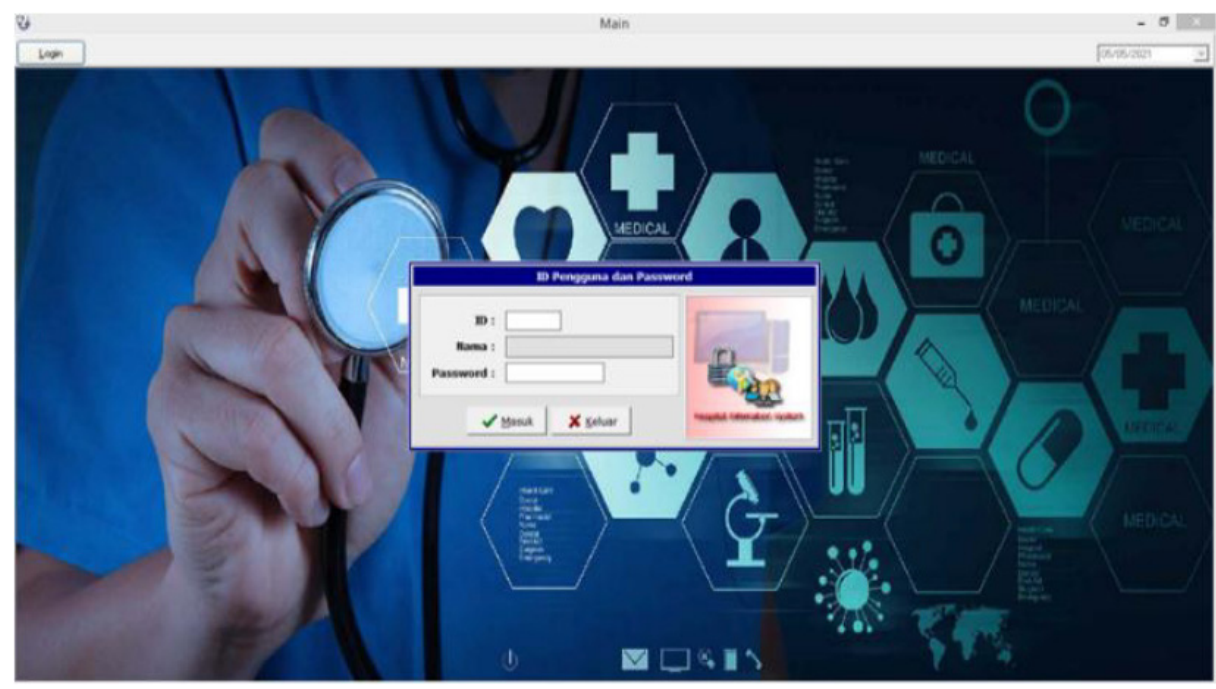

Gambar 3. Tampilan login sistem informasi pengelolaan alat kesehatan di ruang perawatan.

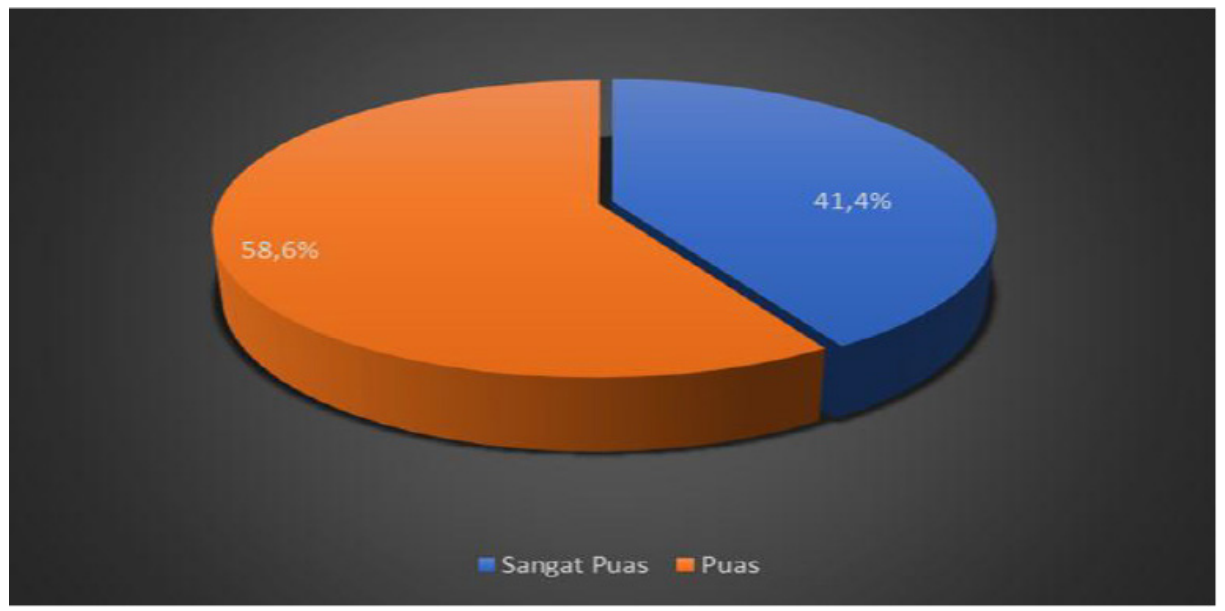

Gambar 4. Kategori kepuasan pengguna (user) berdasarkan kuisioner End User Computing Satisfaction (EUCS) terhadap rancangan sistem informasi pengelolaan alat Kesehatan di ruang perawatan RSUD Sanjiwani Gianyar tahun $2021(n=29)$.

pengelolan alat kesehatan sudah dapat dilakukan secara terintegrasi antara unitunit yang terkait. Adapun user utama dalam sistem informasi ini adalah kepala ruangan, Instalasi Pemeliharaan Sarana Rumah Sakit (IPSRS), bagian pengadaan dan pengurus barang. Disamping user tersebut, terdapat pula bidang keperawatan dan sub bidang perencanaan yang secara tidak langsung terlibat dalam pengelolaan alat kesehatan ini. Adapun alur kerja dari Sistem Informasi Pengelolaan Alat Kesehatan Ruangan (SIPAKAR) dan tampilan awalnya dapat dilihat pada
Gambar 2.

\section{Sosialisasi dan Uji Coba}

Pada tahap ini peneliti dengan didampingi oleh perwakilan IT Rumah Sakit mempresentasikan rancangan sistem cara penggunannya serta membagikan draf petunjuk teknis yang telah dibuat. Secara umum sistem informasi yang telah dirancang dapat diterima oleh user. Adapun tampilan atau user interface tampilan login pengguna terdapat pada Gambar 3. yang telah dibuat, mendemonstrasikan

\section{Evaluasi Kepuasan User Terhadap Rancangan Sistem Informasi}

Berdasarkan hasil evaluasi kepuasan user terhadap sistem informasi yang telah dirancang dengan mengunakan kuesioner EUCS yang didalamya meliputi isi, akurasi, tampilan, kemudahan penggunaan dan ketepatan waktu. Peneliti melakukan penghitungan total skor dari masing-masing partisipan yang kemudian dikategorikan menjadi sangat puas, puas, cukup puas dan kurang puas. Berdasarkan hasil perhitungan sesuai kategori tersebut diketahui bahwa sebagian besar pengguna (user) merasa puas (58,6\%) (Gambar 4).

\section{Evaluasi Manfaat Sistem Informasi yang telah diterapkan}

Berdasarkan hasil evaluasi manfaat nyata yang didapatkan dari penggunaan sistem informasi yang telah dirancang meliputi peningkatan fungsi untuk berbagi pengetahuan, keefektifan komunikasi, mengurangi waktu pencarian informasi dan meningkatkan produktivitas. Peneliti melakukan penghitungan total skor dari masing-masing partisipan yang kemudian dikategorikan menjadi sangat bermanfaat, bermanfaat, cukup bermanfaat dan kurang bermanfaat. Hasil penelitian ini menunjukkan bahwa respon pengguna terhadap penilaian manfaat secara nyata menunjukkan bahwa sebagian besar menyatakan bermanfaat (51,7\%) (Gambar 5).

\section{PEMBAHASAN}

Metode Focus Group Discussion (FGD) merupakan salah satu metode pengumpulan data penelitian dengan hasil akhir memberikan data yang berasal dari hasil interaksi sejumlah partisipan suatu penelitian. FGD pada penelitian ini dibagi menjadi dua sesi, hal ini dilakukan agar jumlah peserta tidak terlalu banyak sehingga diskusi berjalan lebih efektif dan semua peserta FGD mendapat kesempatan untuk menyampaikan pendapatnya. Halini sesuai pendapat Litosseliti dalam Herlinda dimana disampaikan bahwa FGD adalah diskusi kelompok kecil, dengan partisipan yang dipilih dan dipandu moderator, demi menggali topik spesifik, pandangan dan pengalaman individu melalui interaksi kelompok. ${ }^{8}$

Tujuan FGD adalah untuk 


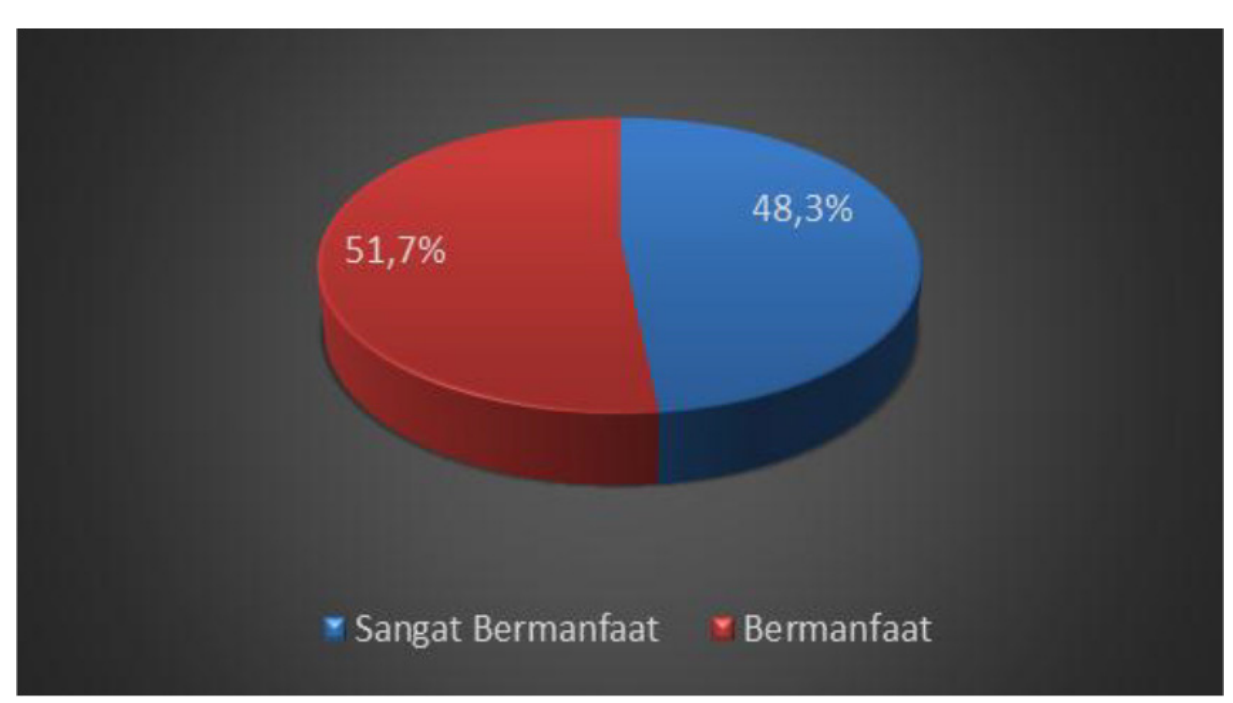

Gambar 5. Kategori respon pengguna (user) terhadap manfaat nyata pengembangan sistem informasi pengelolaan alat kesehatan di ruang perawatan di RSUD Sanjiwani Gianyar Tahun 2021.

mengeksplorasi masalah yang spesifik berkaitan dengan topik yang dibahas. Teknik ini bertujuan untuk menghindari pemahaman yang salah dari peneliti terhadap topik yang diteliti. ${ }^{9}$ Berdasarkan hasil FGD didapatkan tiga belas tema terkait hal-hal yang dibutuhkan oleh user yang berperan sebagai partisipan dalam penelitian ini. Semua tema tersebut terkait dengan fungsi - fungsi manajerial kepala ruangan dalam melakukan pengelolaan alat kesehatan yang meliputi fungsi perencanaan, pengorganisasian, pengarahan dan pengendalian. Tema yang ditemukan ini kemudian diintegrasikan kedalam sistem informasi yang dirancang.

Sistem informasi merupakan bagian dari sistem informasi manajemen yang bertanggung jawab untuk mengidentifikasi kebutuhan informasi, memproses, serta menyediakan informasi dalam bentuk format yang sesuai, sehingga dapat dipergunakan dalam proses pengambilan keputusan. ${ }^{10}$

Dalam penelitian ini, alur untuk pengembangan sistem informasi disesuaikan dengan SPO pengembangan sistem informasi baru yang berlaku di RSUD Sanjiwani Gianyar dan dalam proses perancangannya mengacu metode perancangan sistem informasi model waterfall. Metode waterfall ini merupakan salah satu model dalam perancangan piranti lunak. ${ }^{11}$ Model Waterfall (air terjun) terdiri dari berbagai fase yang tidak tumpang tindih, seperti: Elisitasi dan Analisis Persyaratan, desain, implementasi Sistem, pengujian, penyebaran, pemeliharaan. Dalam model air terjun, sebelum satu fase selesai fase lain tidak dimulai. ${ }^{12}$

Berdasasarkan penelitian yang dilakukan oleh Fuaddi dan Sabarguna (2018), didapatkan bahwa dengan penggunaan sistem informasi dalam pengelolan alat kesehatan, dapat membantu teknisi serta manajemen dalam mengelola sistem pemeliharaan dan kalibari alat Kesehatan, serta menyediakan data bagi pokja MFK dalam akreditasi rumah sakit. ${ }^{13}$

Terdapat perbedaan antara sistem informasi pengelolaan alat kesehatan di ruang perawatan yang telah peneliti rancang dengan beberapa sistem informasi pengelolaan alat kesehatan yang telah peneliti sampaikan pada penelitian terkait. Kebanyakan penelitian tersebut lebih banyak membahas pengelolaan alat kesehatan dari sudut pandang petugas elektromedis, seperti halnya pada penelitian tentang penggunaan sistem informasi pencatatan alat kesehatan untuk mendukung tugas elektromedis dalam pengelolaan alat medik dan penelitian tentang sistem informasi pengelolaan peralatan medik. ${ }^{14,15}$ Pada penelitian ini, sistem informasi yang dihasilkan lebih banyak memfasilitasi fungsi-fungsi manajerial kepala ruangan dalam melakukan pegelolaan alat kesehatan diruangannya, dan sudah mengintegrasikan data dari bagian-bagian yang terlibat dan berhubungan dengan alat kesehatan di ruangan perawatan seperti IPSRS, pengurus barang dan bagian pengadaan alat kesehatan rumah sakit. Integrasi data dalam sistem informasi ini.

Pada tahap ketiga dari penelitian ini, peneliti mengundang kembali partisipan untuk diberikan sosialisasi terkait sistem informasi yang telah dirancang. Tujuan dari sosialisasi ini adalah agar user mengetahui dan memahami sistem yang telah dirancang sehingga dapat memberikan masukan untuk penyempurnaan sistem ini. Setelah dilakukan sosialisasi, perlu juga dilakukan uji coba terhadap sistem tersebut. Hal ini sesuai dengan teori dalam model waterfall, dimana setelah pengkodean selesai maka akan dilakukan testing terhadap sistem yang telah dibuat. Tujuan testing adalah menemukan kesalahan-kesalahan terhadap sistem tersebut untuk kemudian bisa diperbaiki. ${ }^{16}$ Secara umum seluruh pengguna (user) sudah dapat menerima sistem informasi ini.

Tahapan berikutnya adalah melakukan evaluasi untuk menilai kepuasan user terhadap sistem informasi yang telah dirancang. Kepuasan pengguna (user) merupakan suatu penentu bagi keberhasilan penerapan suatu sistem informasi rumah sakit. Metode yang digunakan untuk mengevaluasi sistem informasi adalah End User Computing Satisfaction (EUCS). ${ }^{17}$

Berdasarkan hasil evaluasi didapatkan bahwa $41,4 \%$ menyatakan sangat puas dan $58,6 \%$ menyatakan puas terhadap rancangan sistem informasi yang telah dibuat. Berdasarkan hal tersebut peneliti berasumsi bahwa secara umum peneliti dan tim IT sudah dapat memfasilitasi keinginan dan kebutuhan user yang merupakan partisipan dalam penelitian ini, kedalam rancangan sistem informasi pengelolaan alat kesehatan di ruang perawatan yang selanjutnya peneliti namakan SIPAKAR (Sistem Informasi Pengelolaan Alat Kesehatan Ruangan).

Aplikasi atau penerapan sistem informasi merupakan langkah kelima dari tahapan penelitian ini. Menurut studi yang dilakukan oleh Syam AD dan 
Sukihananto, sampai saat ini, masalah yang paling penting dalam keberhasilan penerapan teknologi informasi adalah penerimaan dan penggunaan teknologi oleh pengguna, sehingga tahapan ini tidak kalah penting dari tahap - tahap lainnya. ${ }^{18}$ Sedangkan menurut Topan $\mathrm{M}$ et al., penerapan sistem informasi oleh user perlu dilakukan selama empat minggu sebelum sistem tersebut dievaluasi. ${ }^{16} \mathrm{Hal}$ ini telah sesuai dengan langkah yang telah dilakukan dalam penelitian ini Tahapan ini merupakan tahapan yang paling panjang. Sistem dipasang dan digunakan secara nyata dan melibatkan pembetulan kesalahan yang tidak ditemukan pada tahapan-tahapan sebelumnya, meningkatkan implementasi dari unit sistem, dan meningkatkan layanan sistem sebagai kebutuhan baru. ${ }^{19}$ Sejalan dengan pendapat tersebut, dalam pelaksanaannya terdapat beberapa kendala teknis dan masukan dari user terkait sistem informasi yang dikembangkan ini, yang meliputi :menu yang dibuka sebelumya, belum bisa tertutup secara otomatis ketika kita berpindah ke menu lain, sehingga tampilan layar terkesan tidak rapi, masih perlu dilakukan penyederhanaan terhadap langkah-langkah dalam proses penginputan perencanaan, daftar usulan yang sudah diinput belum dapat dilihat kembali oleh kepala ruangan dan inventaris, pengurus barang belum bisa melihat inventaris alat di masingmasing ruangan, notif untuk laporan kerusakan alat ke IPSRS belum berfungsi. Dalam rentang waktu penerapan sistem informasi ini, kendala dan masukanmasukan tersebut sudah dapat difasilitasi oleh peneliti dan tim IT.

Pada tahap akhir penelitian ini, dilakukan evaluasi terhadap net benefit (maanfaat nyata) dari pengembangan sistem informasi ini. Net benefit merupakan sejauh mana sistem informasi membantu keberhasilan individu, kelompok, maupun organisasi, khususnya dalam bidang kesehatan. ${ }^{20,21}$ Setelah dilakukan pengelompokkan terhadap total skor dari masing-masing partisipan didapatkan bahwa, 48,3\% peserta menyatakan bahwa sistem informasi ini sangat bermanfaat dan $51,7 \%$ menyatakan bermaanfaat. Sesuai hasil tersebut dapat peneliti berasumsi bahwa sistem informasi ini bermanfaat bagi partisipan dalam melaksanakan tugas dan fungsinya terkait pengelolaan alat kesehatan di ruang perawatan.

Hasil evaluasi terhadap manfaat nyata ini sejalan dengan hasil evaluasi kepuasan user terhadap rancangan sistem informasi ini, dimana $41,4 \%$ menyatakan sangat puas dan $58,6 \%$ menyatakan puas terhadap rancangan sistem informasi pengelolaan alat kesehatan ini. Sejalannya hasil kedua evaluasi ini sesuai dengan pendapat DeLone dan McLean dimana disampaikan bahwa agar sistem informasi manajemen sukses dan mempunyai dampak positif terhadap organisasi maka terlebih dahulu sistem informasi harus mempunyai dampak pada individu. Agar mempunyai dampak terhadap individu maka kepuasan pemakai haruslah tercapai di samping bahwa sistem sudah mulai digunakan secara rutin operasional. ${ }^{6}$

Penelitian yang dilakukan ini masih memiliki keterbatasan yaitu peneliti belum melibatkan bagian perencanaan rumah sakit sebagai user dalam sistem informasi ini, sehingga belum terintegrasi sepenuhnya dengan seluruh komponen yang berperan dalam pengelolaan alat kesehatan ini.

\section{SIMPULAN}

Berdasarkan pemaparan di atas maka dapat disimpulkan bahwa telah teridentifikasi kebutuhan user terkait pengembangan sistem informasi pengelolaan alat kesehatan di ruang perawatan menjadi tiga belas tema. Hasil Evaluasi kepuasan user terhadap rancangan sistem informasi menunjukan bahwa $41,4 \%$ menyatakan sangat puas dan $58,6 \%$ menyatakan puas terhadap rancangan sistem informasi pengelolaan alat kesehatan di ruang perawatan. Sedangkan hasil Evaluasi manfaat nyata (Net Benefit) terhadap pengembangan sistem informasi ini menunjukkan bahwa 48,3\% menyatakan sangat bermanfaat dan $51,7 \%$ menyatakan sistem informasi ini bermanfaat.

\section{KONFLIK KEPENTINGAN}

Penulis menyatakan tidak memiliki konflik kepentingan terkait publikasi dari penelitian ini.

\section{PERSETUJUAN ETIK}

Penelitian ini telah mendapatkan persetujuan etik dari Komite Etik Penelitian ITEKES Bali no. 03.0087/ KEPITEKES-BALI/II/2021 tanggal 22 Februari 2021 dan Panitia Etik Penelitian Kesehatan RSUD Sanjiwani Gianyar no. 19/PEPK/III/2021 tanggal 4 Maret 2021. Disamping itu, penulis juga telah mendapatkan ijin penelitian dari RSUD Sanjiwani Gianyar dengan nomor surat 070/5702/RSU tanggal 6 Maret 2021.

\section{PENDANAAN}

Penulis menyatakan penelitian dilakukan secara swadana tanpa melibatkan pihak sponsor manapun.

\section{KONTRIBUSI PENULIS}

Penulis pertama melakukan penyusunan konsep, desain, definisi konten intelektual; melakukan pencarian literatur, studi dokumentasi, identifikasi kebutuhan user, akuisisi data, analisis data, sosialisasi sistem informasi, analisis statistik; menyusun, memperbaiki dan menyelaraskan manuskrip. Penulis kedua melakukan penyusunan konsep, desain, definisi konten intelektual; melakukan pencarian literatur, akuisisi data, analisis data, analisis statistik; menyusun, memperbaiki dan menyelaraskan manusri dan sebagai penjamin publikasi penelitian. Penulis ketiga melakukan penyusunan konsep, desain, definisi konten intelektual; melakukan pencarian literatur, akuisisi data, analisis data; menyusun, memperbaiki dan menyelaraskan manuskrip. Penulis keempat melakukan penyusunan konsep, desain, definisi konten intelektual; melakukan pencarian literatur, akuisisi data, analisis data, menyusun, memperbaiki dan menyelaraskan manuskrip.

\section{DAFTAR PUSTAKA}

1. Syahrullah, Ngemba HR, Hendra S. Evaluasi EMR Menggunakan Model EUCS. Semnasteknomedia Online. 2016;4(1):6-7.

2. Julianto M. Peran dan Fungsi Manajemen Keperawatan dalam Manajemen Konflik. Fatmawati Hospital Journal. 2014;1:1-9.

3. Jamshidi A, Rahimi SA, Ait-Kadi D, Bartolome AR. Medical devices inspection and maintenance; a literature review. IIE Annu Conf Expo 2014. 2014;1:3895-904. 
4. Alsohime F, Temsah MH, Hasan G, Al-Eyadhy A, Gulman S, Issa $\mathrm{H}$, et al. Reporting adverse events related to medical devices: A single center experience from a tertiary academic hospital. PLoS One. 2019;14(10):e0224233.

5. Sugiono. Metode Penelitian Tindakan (Action Research). Pros Semin Nas Jur PGSD FIP UNP Tahun 2015. 2015;1(1):1-120.

6. Adrianti H, Usman H. Pengaruh Faktor End User Computing Satisfaction (EUCS) Terhadap Manfaat Nyata Pengguna Sistem Informasi Elektronik (E-Puskesmas) di Puskesmas Sawah Besar Jakarta. INOHIM. 2018;6(2):63-69.

7. Nurjaya D. Pengaruh Kualitas Sistem, Informasi Dan pelayanan terhadap manfaat bersih dengan menggunakan model Delone and McLean [Skripsi]. Universitas Sanata Dharma Yogyakarta. 2017

8. Herlinda. Prototipe Web KMS pada Universitas Sebagai Sarana Komunikasi Dosen dengan Kerangka Kerja "Tiwana." J String. 2017;1(3):325-334.

9. Paramita A, Kristiana L. Teknik Focus Group Discussion dalam Penelitian Kualitatif. Buletin Penelitian Sistem Kesehatan. 2013;16(2):11727.

10. Rofii M. Pengembangan Sistem Informasi Sumber Daya Manusia Keperawatan Rumah Sakit. Jurnal Ilmu dan Teknologi Kesehatan. 2011;2(1):15-21.
11. Topan M, Najoan XBN. Perancangan Sistem Informasi Manajemen Rumah sakit berbasis web. J Tek Inform. 2015;6(1):1-6.

12. Lalband N, Kavitha D. Software engineering for smart healthcare applications. Int J Innov Technol Explor Eng. 2019;8(6S4):325-331.

13. Fuaddi M, Sabarguna BS. The Implementation and Testing of a Prototype for Web-Based Medical Equipment Maintenance System. Proc2nd 2018 Int Conf Electr Eng Informatics, ICELTICs 2018. 2018;159-163.

14. Mulyono, Supriyanto, Nugroho AS. Sistem Pencatatan Alat Kesehatan Untuk Mendukung Tugas Elektromedis dalam Pengelolaan Alat Medik. Jurnal Ilmu dan Teknologi Kesehatan. 2016;9(2):53-63.

15. Firmansyah A, Utomo B, Mak'ruf MR. Sistem Informasi Pengelolaan Peralatan Medik ( Analisis Respon Time data layanan komplain). Digilib Poltekkes Depkes Surabaya. 2018:1-12.

16. Topan M, Wowor HF, Najoan XBN. Perancangan Sistem Informasi Manajemen Rumah Sakit Berbasis Web Studi Kasus: Rumah Sakit TNI AU Lanud Sam Ratulangi. E - J Tek Inform. 2015;6(1):1-6.

17. Alfiansyah G, Fajeri AS, Santi MW, Swari SJ. Evaluasi Kepuasan Pengguna. Eval Kepuasan Pengguna Electron Heal Rec Menggunakan Metod EUCS (End User Comput Satisf di
Unit Rekam Medis Pus RSUPN Dr Cipto Mangunkusumo. J Penelit Kesehat Suara Forikes. 2020;11(3):258-263.

18. Syam AD, Sukihananto. Manfaat dan Hambatan dalam Pelaksanaan Sistem Informasi Keperawatan. Jurnal Keperawatan Muhammadiyah. 2019;4(Suppl 1):156-164.

19. Sasmito GW. Penerapan Metode Waterfall Pada Desain Sistem Informasi Geografis Industri Kabupaten Tegal. J Inform Pengemb IT. 2017;2(1):6-12.

20. Herlambang AD, Wijoyo SH, Rachmadi A, Alimah CFN. Evaluasi Berbasis Kriteria untuk Kesusksesan Implementasi Sistem Informasi Kesehatan Berdasarkan Delone and Mclean Model. J Teknol Inf dan Ilmu Komput. 2019;6(3):315-320.

21. Gorji HA, Khalilnezhad R, Bayat M. Human resources challenges in health system reforms: A systematic review. Bali Medical Journal. 2018;7(1):255-261.

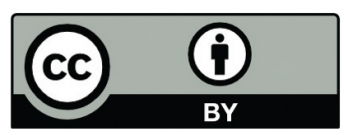

This work is licensed under a Creative Commons Attribution 